\title{
Laparoscopic and endoscopic cooperative surgery for non-ampullary duodenal epithelial neoplasms
}

\author{
Hiroki Toma ${ }^{1}$, Kazuhiro Haraguchi ${ }^{2}$, Kei Fujii ${ }^{1}$, Tomonari Kobarai ${ }^{1}$, Ichio Hirota ${ }^{1}$, Toru Eguchi ${ }^{1}$ \\ 'Department of Surgery, Harasanshin Hospital, Fukuoka 8120033, Japan. \\ Department of Gastroenterology, Harasanshin Hospital, Fukuoka 8120033, Japan.
}

Correspondence to: Dr. Hiroki Toma, Department of Surgery, Harasanshin Hospital, Fukuoka 8120033, Japan.

E-mail: toma@surg1.med.kyushu-u.ac.jp

How to cite this article: Toma H, Haraguchi K, Fujii K, Kobarai T, Hirota I, Eguchi T. Laparoscopic and endoscopic cooperative surgery for non-ampullary duodenal epithelial neoplasms. Mini-invasive Surg 2018;2:21.

http://dx.doi.org/10.20517/2574-1225.2018.24

Received: 10 May 2018 First Decision: 25 Jun 2018 Revised: 13 Jul 2018 Accepted: 20 Jul 2018 Published: 31 Jul 2018

Science Editor: Charles F. Bellows Copy Editor: Jun-Yao Li Production Editor: Huan-Liang Wu

\begin{abstract}
Aim: We herein describe our initial experience of laparoscopic and endoscopic cooperative surgery (LECS) for nonampullary duodenal epithelial neoplasms (NADENs) and reveal its clinical significance.

Methods: This study included 5 consecutive patients treated by LECS for NADENs between April 2015 and January 2016 in our hospital. For surgery, RO-resection of NADENs was accomplished by endoscopic submucosal dissection (ESD), and the mucosal defect resulting from ESD was subsequently repaired by laparoscopic seromuscular suture and endoscopic clipping. Clinical records were reviewed retrospectively.
\end{abstract}

Results: LECS was accomplished in four patients. There was a case of open conversion due to the relatively large mucosal defect resulting from ESD. In the postoperative course, no serious complications, including intra- and postoperative bleeding and delayed perforation, were noted. The duodenal stenosis occurred in the case of open conversion but was treated by repeated endoscopic balloon dilatation. Of the five lesions of NADENs, there were three adenomas and two adenocarcinomas confined in the mucosa. To date, no tumor recurrence was observed during the postoperative course.

Conclusion: LECS is a promising procedure of choice in the treatment of NADENs, facilitating early resumption of both food intake and full daily activity in the postoperative course.

Keywords: Endoscopic submucosal dissection, laparoscopic and endoscopic cooperative surgery, non-ampullary duodenal epithelial neoplasms

\footnotetext{
(@) (

(C) The Author(s) 2018. Open Access This article is licensed under a Creative Commons Attribution 4.0 International License (https://creativecommons.org/licenses/by/4.0/), which permits unrestricted use, sharing, adaptation, distribution and reproduction in any medium or format, for any purpose, even commercially, as long as you give appropriate credit to the original author(s) and the source, provide a link to the Creative Commons license, and indicate if changes were made.
} 


\section{INTRODUCTION}

Recent advances in gastrointestinal endoscopic technology and diagnostic skills have led to increased occurrence of asymptomatic non-ampullary duodenal epithelial neoplasms (NADENs) in daily clinical practice $^{[1-3]}$. Either endoscopic mucosal resection (EMR) or submucosal dissection (ESD) has occasionally been indicated in the treatment of NADENs, but the procedure remains technically challenging, given that expertise in both meticulous dissection and subsequent repair is required in the narrow lumen of the duodenum $^{[2-5]}$. In addition, the prevention of bleeding and perforation during and after the procedure is pivotal, given that the incidence of these serious complications is relatively frequent in ESD for NADENs ${ }^{[4-6]}$.

Laparoscopic and endoscopic cooperative surgery (LECS) was initially invented for the purpose of less invasive surgery for gastric non-epithelial neoplasms ${ }^{[7]}$ but later employed to overcome the limitation of ESD for early gastric cancer (e.g., non-exposed wall inversion surgery $\left(\mathrm{NEWS}^{[8]}\right)$, a combination of laparoscopic and endoscopic approaches to neoplasia using non-exposure techniques (CLEAN-NET ${ }^{[9]}$ ). Similarly, recent reports demonstrated that LECS offers a promising procedure of choice to facilitate less invasive surgery in the treatment of NADENs ${ }^{[10-15]}$, but the clinical evidence verifying its efficacy remains limited. In this report, we sought to investigate our initial experience of LECS for NADENs and further reveal its clinical significance. Our LECS procedure including ESD and subsequent laparoscopic and endoscopic repair may extend the indication of ESD and improve its safety in the treatment of NADENs.

\section{METHODS}

Five consecutive patients with the diagnosis of NADENs between April 2015 and January 2016 were included in this study. All of the patients were referred to the department of surgery by the gastroenterologists. LECS for NADENs was indicated for these patients following routine preoperative examination including esophagogastroduodenoscopy with concomitant biopsy, endoscopic ultrasonography (EUS), upper GI series and computed tomography (CT). Gastroenterologists and surgeons had deliberate discussion to determine the surgery indication for all of patients. In the discussion, special attention was given to the distance between NADENs and Vater papilla obtained from upper GI series images in view of both the prevention of the injury to Vater papilla and the security of the resection margin at least $10 \mathrm{~mm}$ away from Vater papilla. Epithelial neoplasms confined in the mucosa at the risk of malignancy were eligible for treatment. In principle, NADENs located in the duodenal wall side of the pancreas head were preoperatively contraindicated for LECS, given that laparoscopic suture repair following ESD was considered to be rather demanding. All of the patients consequently provided written informed consent prior to surgery. Clinical records were reviewed retrospectively. Clinical outcomes included operation time, blood loss, intra- and postoperative complications, and length of postoperative hospital stay. Postoperative complications were graded according to the Clavien-Dindo Classification (C-D: Grade ${ }^{[16]}$ ). All patients were followed up in the outpatient clinic after the discharge. The follow-up examination included the endoscopy during the first postoperative year. In cases with malignancy in the final diagnosis, CT was also periodically performed in the outpatient clinic.

\section{LECS procedure for NADENS}

The surgery of LECS for NADENs was performed by a single surgeon (HT) with the certification of Japan Society for Endoscopic Surgery. The patient was placed in a supine position with both legs apart under general anesthesia. A total of five ports were inserted in the abdomen, as described in Figure 1, and the pneumoperitoneum was created and maintained at approximately 8 to $10 \mathrm{mmHg}$. The operative field was visualized by 3 -dimensional imaging systems equipped with a $10 \mathrm{~mm}$ flexible scope (Olympus, Tokyo, Japan) through the infraumbilical port. The infrapyloric region was reached by the dissection of the greater omentum in the vicinity of the transverse colon with an ultrasonically activated scalpel. Following the adequate mobilization of the duodenum, the upper jejunum around $10-20 \mathrm{~cm}$ away from Treiz ligament was 


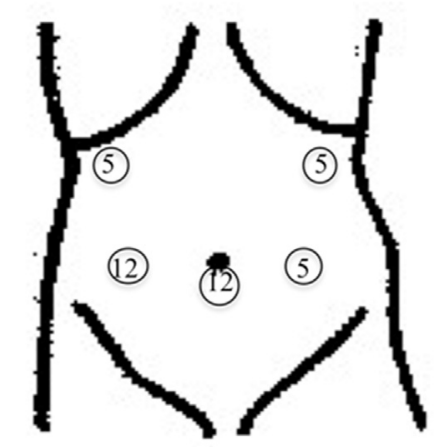

Figure 1. Port site. The value in the circle indicates the size of each port inserted in the abdomen

temporarily occluded with the laparoscopic intestinal clamper, and ESD was commenced by the gastroenterologist (KH with the certification of Japan Gastroenterological Endoscopy Society). The localization of NADENs was confirmed endoscopically and thereafter treated by regular ESD. Considerable attention was given to avoid Vater papilla injury during the procedure. The mucosa approximately $2-3 \mathrm{~mm}$ away from NADENs was circumferentially incised with either a flush knife or clutch cutter after local injection of the sodium hyaluronate solution around NADENs. Subsequently, the dissection was meticulously made, and the specimen was contained in the pouch and retrieved orally. Endoscopic dye injection (either indigocarmine or indocyanine green) to the ulcer bed enabled the immediate identification and repair of the mucosal defect from serosal side under laparoscopy. Intracorporeal-interrupted seromuscular sutures with 4-0 PDS (Johnson \& Johnson, Cincinnati, OH) were made in perpendicular direction to the long axis of the duodenum. In addition, the mucosal defect was repaired with clips under endoscopy. Airtightness in the suture line was confirmed by sufficient inflation of the duodenum by endoscopy, and the laparoscopic intestinal clamper was finally retrieved before the release of the pneumoperitoneum.

\section{RESULTS}

Patient characteristics, preoperative and pathological data are presented in Table 1. This study included four males and one female, and the age at surgery ranged from 41 to 69 years old. In preoperative data, none of the five NADENs was malignant in biopsy and all of the lesions were supposed to be confined in the mucosa in EUS. In CT, neither regional lymph node swelling nor distant metastasis was shown in all of the patients. Of the five NADENs, there were three adenomas and two adenocarcinomas confined in the mucosa based on the pathological reports in the postoperative course. All of the lesions treated by LECS were located in the second portion of the duodenum. The distance between NADENs and Vater papilla was measured in the upper-GI series images in all of the patients and ranged from 14 to $32 \mathrm{~mm}$. In cases 2 and 3, NADENs were observed in the vicinity of Vater papilla (15 $\mathrm{mm}$ in case 2, $14 \mathrm{~mm}$ in case 3), but the indication of LECS was approved, given that the lesions were not located in contact with the pancreas head. The representative NADENs images from case 3 are presented in Figure 2. The section of the LECS for NADENs procedure is presented in Figure 3. The operative results are presented in Table 2. The total operation time ranged from 152 to 552 (mean 264) min. In case 5, the relatively large mucosal defect resulting from ESD (tumor size: $54 \mathrm{~mm} \times 47 \mathrm{~mm}$ in Table 1) for NADENs resulted in the only open conversion during the procedure in this study [Table 2]. Following the laparotomy, full thickness suture repair of the duodenum was performed under the direct vision. In ESD, R0-resection was accomplished in all of the patients. The active bleeding during ESD was mainly treated with the electrocoagulation. In case 1, microperforation occurred during ESD, but was successfully repaired by subsequent clipping under endoscopy. With regard to postoperative complications, the duodenal stenosis in case 5 was treated by endoscopic balloon dilatation for four times during the hospital stay (C-D: Grade IIIa), but bleeding and perforation were not noted during the procedure and postoperative course. In all of the patients treated with LECS for 

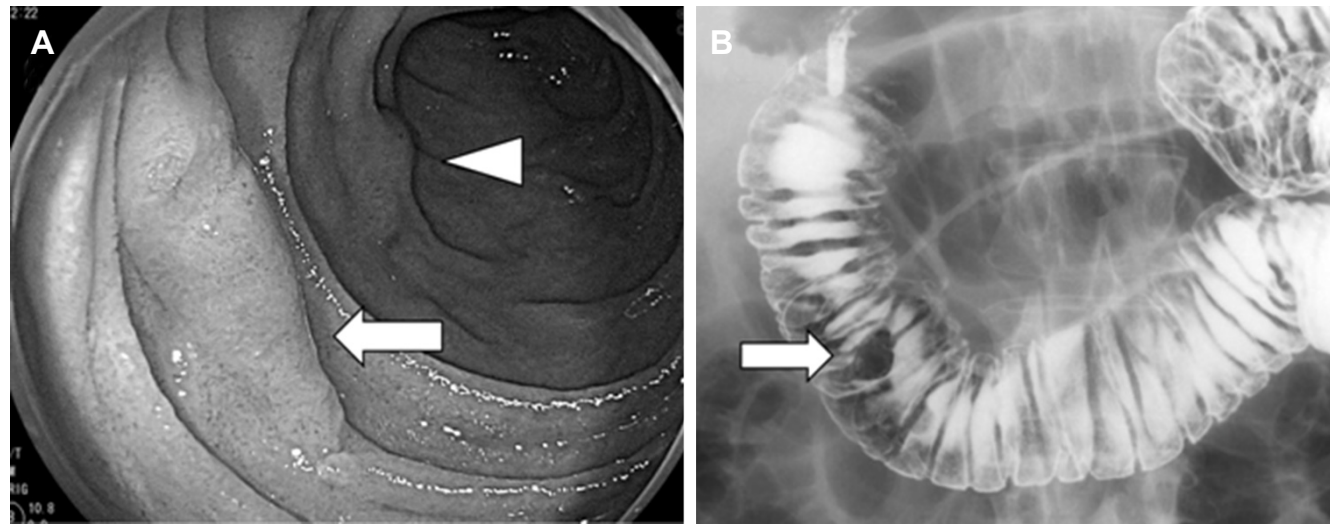

Figure 2. Representative images of NADENs from case 3. (A) Endoscopic image, arrow: NADENs, arrowhead: Brunner gland; (B) upper GI series images, arrow: NADENs
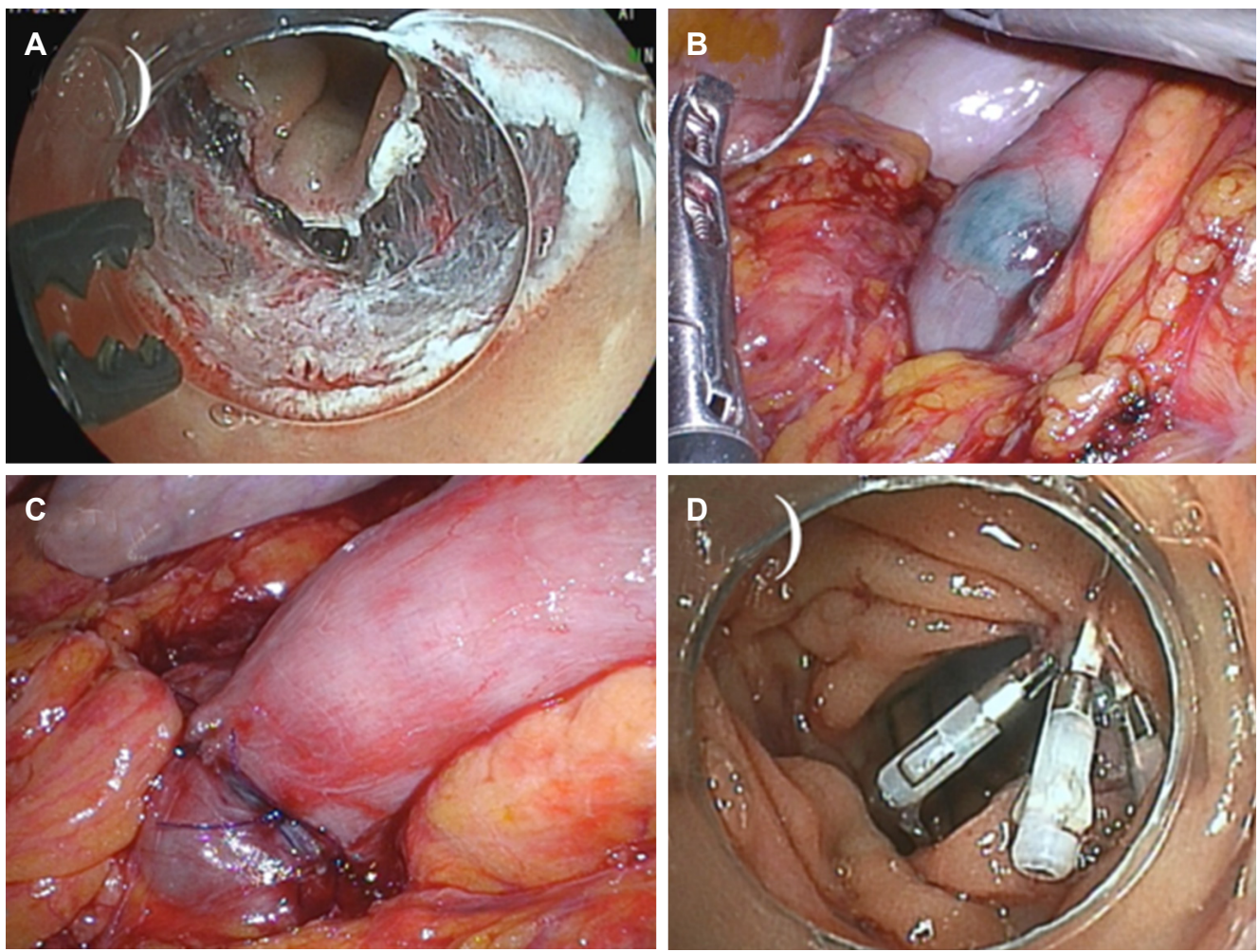

Figure 3. Operative findings. (A) The mucosal defect resulting from ESD; (B) the endoscopic dye injected into the ulcer bed allowed for the immediate identification of the duodenal lesion under laparoscopy; (C) intracorporeal interrupted seromuscular sutures were made along the right direction of the long axis of the duodenum; (D) the mucosal defect was further repaired with clips under endoscopy

NADENs, both vertical and horizontal margins of the specimen were free of tumor cells. In the postoperative course, the patients with the exception of case 5 resumed food intake on postoperative days (POD) 3-5 and full daily activity on the day of discharge. In case 5, the liquid diet was allowed to take on POD 38 and normal diet on POD47. The patient resumed full daily activity at the discharge of POD 49. In the outpatient clinic, follow-up endoscopy was performed for all of the patients during the first postoperative year, and CT was performed for the two patients with adenocarcinomas for every 6 months. To date, neither tumor recurrence nor metastasis was noted in any of the patients. 
Table 1. Patient characteristics, preoperative and pathological data

\begin{tabular}{|c|c|c|c|c|c|c|c|c|c|c|c|}
\hline $\begin{array}{l}\text { Case } \\
\text { No. }\end{array}$ & Age & Gender & $\begin{array}{l}\text { Tumor } \\
\text { location }\end{array}$ & $\begin{array}{c}\text { Distance } \\
\text { from } \\
\text { papilla } \\
(\mathrm{mm})\end{array}$ & CT & EUS & Biopsy & $\begin{array}{l}\text { Macro-scop- } \\
\text { ic appear- } \\
\text { ance }\end{array}$ & Postop pathology & $\begin{array}{l}\text { Tumor } \\
\text { size } \\
(\mathrm{mm})\end{array}$ & $\begin{array}{c}\text { Specimen } \\
\text { size } \\
(\mathrm{mm})\end{array}$ \\
\hline 1 & 54 & Male & 2nd portion & 32 & $\mathrm{np}$ & Mucosa & Adenma & II c & Adenoma & $12 \times 7$ & $22 \times 15$ \\
\hline 2 & 41 & Male & 2nd portion & 15 & $\mathrm{np}$ & Mucosa & Adenma & II $c$ & Adenoma & $21 \times 17$ & $31 \times 26$ \\
\hline 3 & 57 & Male & 2nd portion & 14 & $\mathrm{np}$ & Mucosa & Atypia & II a & Adeno-carcinoma & $16 \times 9$ & $29 \times 19$ \\
\hline 4 & 69 & Female & 2nd portion & 21 & $\mathrm{np}$ & Mucosa & Adenma & II c + II a & Adenoma & $14 \times 6$ & $19 \times 14$ \\
\hline 5 & 50 & Male & 2nd portion & 29 & $\mathrm{np}$ & Mucosa & Adenma & II a & Adeno-carcinoma & $54 \times 47$ & $68 \times 55$ \\
\hline
\end{tabular}

In CT, np indicates neither significant regional lymph node swelling nor distant metastasis. Case 5 was the only case of open conversion. Three adenomas and two adenocarcinomas were confined in the mucosa

Table 2. Operative results

\begin{tabular}{|c|c|c|c|c|c|c|c|}
\hline $\begin{array}{l}\text { Case } \\
\text { No. }\end{array}$ & $\begin{array}{l}\text { ESD/total op } \\
\text { time (min) }\end{array}$ & $\begin{array}{l}\text { Blood loss } \\
(\mathrm{mL})\end{array}$ & $\begin{array}{c}\text { Intraop } \\
\text { complications }\end{array}$ & RO-resection & Repair & $\begin{array}{c}\text { Postop } \\
\text { complications }\end{array}$ & $\begin{array}{c}\text { Postop hospital } \\
\text { stay (days) }\end{array}$ \\
\hline 1 & $98 / 228$ & 10 & Micro-perforation & Yes & Suture + clips & None & 7 \\
\hline 2 & 49/152 & 5 & None & Yes & Suture + clips & None & 9 \\
\hline 3 & $56 / 187$ & 30 & None & Yes & Suture + clips & None & 8 \\
\hline 4 & $26 / 202$ & 5 & None & Yes & Suture + clips & None & 8 \\
\hline 5 & $252 / 552$ & 100 & None & Yes & Suture & Stenosis & 49 \\
\hline
\end{tabular}

Micro-perforation during ESD was immediately repaired with clips under endoscopy. Duodenal stenosis occurred in the case of open conversion but was treated by repeated endoscopic balloon dilatation. ESD: endoscopic submucosal dissection

Table 3. Previous reports of LECS for NADENs

\begin{tabular}{|c|c|c|c|c|c|c|c|c|}
\hline Year & Author & No. & $\begin{array}{l}\text { Tumor size } \\
\text { (mean:mm) }\end{array}$ & Repair & $\begin{array}{c}\text { Op time } \\
\text { (mean; min) }\end{array}$ & $\begin{array}{c}\text { No. of } \\
\text { cancer (\%) }\end{array}$ & Conversion & $\begin{array}{c}\text { No. of postop } \\
\text { complications (\%) }\end{array}$ \\
\hline 2010 & Sakon et al. ${ }^{[10]}$ & 2 & 19 & Suture & 168 & $0(0)$ & None & $0(0)$ \\
\hline 2010 & Tsujimoto et al.. ${ }^{[11]}$ & 2 & 21.5 & Suture & 116 & $0(0)$ * & None & $O(0)$ \\
\hline 2014 & Ohata et al. ${ }^{[12]}$ & 22 & 13.3 & Suture & 133 & $6(27.3)$ & None & $5(22.7)$ \\
\hline 2015 & Irino et al. ${ }^{[13]}$ & 3 & 17 & Suture & 234 & $3(100)$ & None & $1(33.3)$ \\
\hline 2015 & Kyuno et $a / .^{[14]}$ & 2 & 12.5 & Suture & 131 & $0(0)$ & None & $0(0)$ \\
\hline 2016 & Ichikawa et al. ${ }^{[15]}$ & 12 & 22 & Suture & 322 & $10(83.3)$ & None & $2(16.7)$ \\
\hline \multirow[t]{2}{*}{2018} & Ojima et al. ${ }^{[20]}$ & 18 & 18 (median) & Suture & 116.5 (median) & $4(38.9)$ & None & $0(0)$ \\
\hline & Our study & 5 & 23.4 & Suture + clips & 264 & $2(40)$ & Yes & $1(20)$ \\
\hline
\end{tabular}

${ }^{\star}$ The final diagnosis of both cases was carcinoid tumors. No. of cancer (\%) indicates the number of cases with cancer in the final diagnosis and its rate of incidence. No. of postoperative complications (\%) indicates the number of cases with postoperative complications and its rate of incidence. Postoperative complications were occasionally documented in previous reports, but treated conservatively (C-D: Grade II or IIla). LECS: laparoscopic and endoscopic cooperative surgery; NADENs: non-ampullary duodenal epithelial neoplasms; C-D: ClavienDindo Classification

\section{DISCUSSION}

In this study, we present our initial experience of LECS for NADENs, which was accomplished in four out of the consecutive five cases. We did not experience serious intra- and postoperative complications (> C-D: Grade IIIb) or tumor recurrence, thereby suggesting the feasibility of our LECS procedure for NADENs, although the results from our small number of case series study remain limited. In our series of cases successfully treated by LECS, early resumption of food intake and full daily activity approximately one week in the postoperative course demonstrated the reduced invasiveness of our LECS procedure for NADENs. There was one case of open conversion due to the relatively large mucosal defect (tumor size: $54 \mathrm{~mm} \times$ $47 \mathrm{~mm}$ in case 5) resulting from ESD in this study, implying the limitation of the indication of our procedure for LECS for NADENs. Abe et al. ${ }^{[17]}$ reported the successful treatment of duodenal GIST, $62 \mathrm{~mm}$ in diameter by laparoscopy-assisted full-thickness resection, where both resection of the lesion and subsequent repair was performed manually under the 5 to $7 \mathrm{~cm}$ upper median laparotomy, suggesting the promising 
alternative to our LECS procedure for large NADENs.

In the literature ${ }^{[10-15]}$, a total seven authors reported a series of LECS for NADENs where the lesions were treated by either ESD and subsequent laparoscopic repair or endoscopy-assisted laparoscopic full-thickness resection and repair without any serious intra- and postoperative complications, corresponding to our results [Table 3]. In those reports, surgery was occasionally performed for adenocarcinomas confined in the mucosa, but no tumor recurrence was noted in the postoperative course, revealing the feasibility of the indication of LECS for NADENs. Regarding the size of NADENs successfully treated with LECS, the mean diameter ranged from 13.3 to $22 \mathrm{~mm}$ [Table 3]. From our experience of only one conversion involving a tumor that was $54 \mathrm{~mm}$ in diameter, LECS might be accomplished for NADENs within approximately $30 \mathrm{~mm}$ in diameter and at least $10 \mathrm{~mm}$ away from Vater papilla.

Our LECS procedure for NADENs is consistent with the previous reports, demonstrating ESD and subsequent laparoscopic repair in the treatment of NADENs ${ }^{[13,14]}$. Complete resection of the lesions by ESD without micro-perforation theoretically enables the avoidance of tumor dissemination in the peritoneal cavity, where the precise preoperative evaluation of the depth of NADENs is inevitable. Furthermore, postoperative analysis of pathological results is critical, given that additional surgery could be required in cases involving margins or vertical invasion beyond the submucosal layer of malignant lesions. Long-term follow-up for patients with malignant results are warranted to verify the oncological feasibility of LECS for NADENs.

Exposure of the epithelial injury in the duodenum to bile and pancreatic juice impairs tissue regeneration ${ }^{[18,19]}$. Consequently, repair of the mucosal defect resulting from ESD is critical for the prevention of postoperative complications in LECS for NADENs. Compared with previous reports ${ }^{[13,14]}$, our procedure for LECS for NADENs is novel in terms of the repair procedure after ESD consisting of the combination of laparoscopic hand-sewn seromuscular suture and endoscopic clipping, enabling the closure of the mucosal defect from both inside and outside the duodenum [Figure 3]. The anticipation of laparoscopic hand-sewn seromuscular sutures contributed to the reduction of the mucosal defect and therefore facilitated subsequent endoscopic clipping, compared with immediate clipping after ESD. In our results, immediate or delayed bleeding and perforation did not occur, revealing the feasibility of repair using LECS for NADENs. The future prevalence of robotic surgery may facilitate the laparoscopic suturing in LECS for NADENs.

Ojima et al. ${ }^{[20]}$ recently reported the operative results of LECS superior to ESD for the treatment of NADENs in the comparative study. They showed the statistically decreased incidence of any postoperative complications including bleeding and perforation in LECS, demonstrating LECS contributed to the improvement in the safety during and after ESD for the treatment of NADENs. To date, clinical data regarding LECS for NADENs derived from the short-term outcomes. Therefore, it should be reminded the long-term oncological outcomes remain to be verified for the establishment of LECS for NADENs. For the moment, the indication of LECS for NADENs requires deliberate consideration before the surgery and should be limited to NADENs at low-risk of biological aggressiveness.

In conclusion, LECS is a promising procedure of choice in the treatment of NADENs, facilitating early resumption of both food intake and full daily activity in the postoperative course. Further accumulation of clinical evidence is warranted for the establishment of the treatment strategy and obtaining long-term results of LECS for NADENs.

\section{DECLARATIONS}

\section{Authors' contributions}

Study concept and design, manuscript preparation: Toma H, Haraguchi K, Eguchi T 
Data collection, literature research: Toma $\mathrm{H}$

Analysis and interpretation of results: Toma H, Haraguchi K, Fujii K, Kobarai T, Hirota I, Eguchi T

\section{Availability of data and materials}

The data is presented and kept by the author and is available for scrutiny.

\section{Financial support and sponsorship}

None.

\section{Conflicts of interest}

All authors declare that there are no conflicts of interest.

\section{Ethical approval and consent to participate}

This study was approved by the ethics committee/institutional review board in our hospital (No2017-33). Informed consent was obtained from all patients for being included in the study.

\section{Consent for publication}

Not applicable.

\section{Copyright}

(c) The Author(s) 2018.

\section{REFERENCES}

1. van Heumen BW, Mul K, Nagtegaal ID, van Kouwen MC, Nagengast FM. Management of sporadic duodenal adenomas and the association with colorectal neoplasms: A retrospective cohort study. J Clin Gastroenterol 2012;46:390-6.

2. Yamamoto Y, Yoshizawa N, Tomida H, Fujisaki J, Igarashi M. Therapeutic outcomes of endoscopic resection for superficial non-ampullary duodenal tumor. Dig Endosc 2014;26 Suppl 2:50-6.

3. Kakushima N, Kanemoto H, Tanaka M, Takizawa K, Ono H. Treatment for superficial non-ampullary duodenal epithelial tumors. World J Gastroenterol 2014;20:12501-8.

4. Bourke MJ. Endoscopic resection in the duodenum. Endoscopy 2013;45:127-32.

5. Matsumoto S, Miyatani H, Yoshida Y. Future directions of duodenal endoscopic submucosal dissection. World J Gastrointest Endosc 2015;7:389-95.

6. Inoue T, Uedo N, Yamashina T, Yamamoto S, Hanaoka N, Takeuchi Y, Higashino K, Ishihara R, Iishi H, Tatsuta M, Takahashi H, Eguchi H, Ohigashi H. Delayed perforation: A hazardous complication of endoscopic resection for non-papillary duodenal neoplasm. Dig Endosc 2014;26:220-7.

7. Hiki N, Yamamoto Y, Fukunaga T, Yamaguchi T, Nunobe S, Tokunaga M, Miki A, Ohyama S, Seto Y. Laparoscopic and endoscopic cooperative surgery for gastrointestinal stromal tumor dissection. Surg Endosc 2008;22:1729-35.

8. Goto O, Mitsui T, Fujishiro M, Wada I, Shimizu N, Seto Y, Koike K. New method of endoscopic full-thickness resection: a pilot study of non-exposed endoscopic wall-inversion surgery in an ex vivo porcine model. Gastric Cancer 2011;14:183-7.

9. Inoue H, Ikeda H, Hosoya T, Yoshida A, Onimaru M, Suzuki M, Kudo SE. Endoscopic mucosal resection, endoscopic submucosal dissection, and beyond: full-layer resection for gastric cancer with nonexposure technique (CLEAN-NET). Surg Oncol Clin N Am 2012;21:129-40.

10. Sakon M, Takata M, Seki H, Hayashi K, Munakata Y, Tateiwa N. A novel combined laparoscopic-endoscopic cooperative approach for duodenal lesions. J Laparoendosc Adv Surg Tech A 2010;20:555-8.

11. Tsujimoto H, Ichikura T, Nagao S, Sato T, Ono S, Aiko S, Hiraki S, Yaguchi Y, Sakamoto N, Tanimizu T, Yamamoto J, Hase K. Minimally invasive surgery for resection of duodenal carcinoid tumors: endoscopic full-thickness resection under laparoscopic observation. Surg Endosc 2010;24:471-5.

12. Ohata K, Murakami M, Yamazaki K, Nonaka K, Misumi N, Tashima T, Minato Y, Shozushima M, Mitsui T, Matsuhashi N, Fu K. Feasibility of endoscopy-assisted laparoscopic full-thickness resection for superficial duodenal neoplasms. Sci World J 2014;2014:239627.

13. Irino T, Nunobe S, Hiki N, Yamamoto Y, Hirasawa T, Ohashi M, Fujisaki J, Sano T, Yamaguchi T. Laparoscopic-endoscopic cooperative surgery for duodenal tumors: a unique procedure that helps ensure the safety of endoscopic submucosal dissection. Endoscopy $2015 ; 47: 349-51$

14. Kyuno D, Ohno K, Katsuki S, Fujita T, Konno A, Murakami T, Waga E, Takanashi K, Kitaoka K, Komatsu Y, Sasaki K, Hirata K. Laparoscopic-endoscopic-cooperative surgery is a safe and effective treatment for superficial nonampullary duodenal tumors. Asian J Endosc Surg 2015;8:461-4.

15. Ichikawa D, Komatsu S, Dohi O, Naito Y, Kosuga T, Kamada K, Okamoto K, Itoh Y, Otsuji E. Laparoscopic and endoscopic co-operative surgery for non-ampullary duodenal tumors. World J Gastroenterol 2016;22:10424-31. 
16. Dindo D, Demartines N, Clavien PA. Classification of surgical complications: A new proposal with evaluation in a cohort of 6336 patients and results of a survey. Ann Surg 2004;240:205-13.

17. Abe N, Hashimoto Y, Takeuchi H, Ohki A, Nagao G, Suzuki Y, Masaki T, Mori T, Sugiyama M. Laparoscopy-assisted full thickness resection of the duodenum for patients with gastrointestinal stromal tumor with ulceration. Asian J Endosc Surg 2017;10:388-93.

18. Honda T, Yamamoto H, Osawa H, Yoshizawa M, Nakano H, Sunada K, Hanatsuka K, Sugano K. Endoscopic submucosal dissection for superficial duodenal neoplasms. Dig Endosc 2009;21:270-4.

19. Fujihara S, Mori H, Kobara H, Nishiyama N, Matsunaga T, Ayaki M, Yachida T, Masaki T. Management of a large mucosal defect after duodenal endoscopic resection. World J Gastroenterol 2016;22:6595-609.

20. Ojima T, Nakamori M, Nakamura M, Hayata K, Katsuda M, Takifuji K, Yamaue H. Laparoscopic and endoscopic cooperative surgery versus endoscopic submucosal dissection for the treatment of low-risk tumors. J Gastrointest Surg 2018;22:935-40. 